\title{
USE OF TECHNOLOGY IN TEACHING ENGLISH
}

${\text { Ayu Pratiwi }{ }^{*}}{ }^{2}$
Elsa Pratiwi $^{2}$
Faradila Chantika $^{3}$
Hamida Putri $^{4}$
Resti Aulia Nengsih $^{5}$
Muhammad Taufik Ihsan

\begin{abstract}
In language coaching and gaining knowledge of, we've got loads to select from the sector of generation: audio, TV, CD Rom, Computers, C.A.L.L., the Internet, Electronic Dictionary, Email, Blogs and Audio Cassettes, Power Point, Videos, DVD's or VCD's. Technology has modified the dynamics of diverse industries, and has additionally encouraged the the manner human beings engage and paintings withinside the society. This speedy growing and improvement of statistics era has supplied a higher sample to discover the brand new coaching version. As a end result era performs a totally vital position in English coaching. Using multimedia to create a context to train English has its particular advantages. The instructors can have interaction the freshmen to grow to be professional at English Language through the usage of the revolutionary ELT strategies like English songs, movie, clippings, dramatics, advertisements, sports activities commentaries and plenty of extra. This paper stresses at the want to make English language training smooth and exciting thru revolutionary ELT techniquesby using a scope review study methodology, which is a literature review process between new theories and ideas, so this paper talk about definition and development of technology, use of generation in coaching English, the boom of elt via generation, and advantages of the use of generation in the classroom.
\end{abstract}

Keywords: English language teaching, Multimedia, Technology.

Published by:

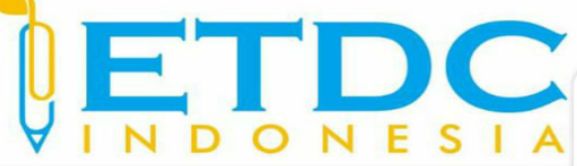

Copyright (C) 2021 The Author (s)

This article is licensed under CC BY 4.0 License

(cc) BY 


\section{USE OF TECHNOLOGY IN TEACHING ENGLISH}

\section{Introduction}

English is a tool for communicating both orally and in writing that is used globally. Just as Indonesian is the unifying language of the Indonesian people from Sabang to Merauke, so English is the unifying language of all nations in the world. English is a tool to drive the flow of globalization both in the fields of science and technology (Science and Technology), politics, socio-culture, and economics. Thus, it is undeniable that English has a very important role in today's global era.

Based on the above, learning English as a foreign language is very important for a number of countries, especially for developing countries like Indonesia. This indicates that English language skills are a must to be mastered by all levels of Indonesian society. Therefore, the Indonesian government through the Ministry of Education and Culture makes English a compulsory subject and is included in the National Examination (UN). It aims to build human resources that are competitive in the global era.

Learning English through the use of technology is an application of science that aims to meet human needs and accelerate the achievement of the goals of each activity that will be carried out. While education can be interpreted narrowly (formal) or broadly (formal or nonformal). In this case, education is interpreted alternatively as a substitute as a aware attempt made through the family, network and authorities via guidance, coaching, and or schooling sports that take region at faculty and out of doors faculty in the course of lifestyles to put together college students on the way to play a function in diverse dwelling environments efficiently. Right withinside the future. Eric Hasby divides revolution in education into 4, namely: First, when society differentiates the role of adults, Second, the use of writing as a means of education, Third, the invention of the printing press and Fourth, the use of advanced technology as the development of the electronic field.

The new technology assigns new demanding situations and obligations at the cuttingedge instructor. The subculture of English coaching has been extensively modified with the awesome access of era. Technology presents such a lot of alternatives as making coaching thrilling and additionally making coaching greater effective in phrases of improvements. Technology is one of the maximum extensive drivers of each social and linguistic alternate. Graddol: (1997:16)states that" era lies on the coronary heart of the globalization method; affecting training paintings and way of life. The use of English language has elevated hastily after 1960. At gift the function and standing of English is that it's far the language of social 
context, political, sociocultural, commercial enterprise, schooling, industries, media, library, conversation throughout borders, and key challenge in curriculum and language of supplying schooling". It isalso a essential determinant for college front and processing nicely paid jobs withinside the business sector. Since there are increasingly English freshmen in India, distinctive coaching techniques were applied to check the effectiveness of the coaching manner. One technique includes multimedia in ELT to be able to create English contexts. This facilitates college students to get concerned and analyze in step with their interests, It has been examined correctly and is broadly conventional for coaching English in contemporary-day global. Technology is applied for the upliftment of present day patterns; it satisfies each visible and auditory senses of the college students. With the unfold and improvement of English round the arena, English has been discovered and utilized by increasingly more speakers. According to David Graddol 'it's far the language on the main fringe of medical and technological improvement, new questioning in economies and management, new literatures andentertainment genre.

.Utilization of technology and media-based Technology in learning is believed to be able to provides many benefits and positive effects. (Ghasemi \& Hashemi, 2011; Khanom, 2018). As stated bymany researchers, implementation of utilization effective technology can increase student motivation in learning, enabling students to see the simulation of direct contactwith the culture and country of the speaker English, providing access to reach material resources from around the world, facilitate learning for students in various learning styles and learning strategies, or can even increase autonomy learner, sharpen critical thinking students, and can also be a process which can be used as a solution for various problems in learning and learning.

The use of generation in getting to know isn't a brand new element, inclusive of the usage of computer systems as studying media wherein there is lots of software program that features to assist schooling. Belisle (1996) proves that "By the use of computer systems, college students grow to be higher capable of resolve troubles and come to be higher communicators. Through laptop networks, college students have the possibility to collaborate and paintings collectively with buddies from different classes, groups, and instructors. These networks can assist beginners create, analyze, and bring statistics and thoughts extra effortlessly and efficiently. In addition, thru digital get admission to, it may boom college students' attention of the arena round them. Today, pc community era performs a main position withinside the global of schooling. We can understand the blessings of pc community generation are felt, with pc networks we will store power and costs. A laptop community is a set of computer systems which are linked to every different. So with a laptop community, computer systems related to it could 
speak with every different. For example, sharing records, hardware, sharing assets, and others. To construct any community, we want gadget that may be used to attach one laptop to another. The device wanted consists of servers, workstations, community cards, concentrators, and community cables. Muehleisen (1997) states that "college students are inquisitive about the usage of the Internet for 3 motives. The first cause, college students view the Internet as a fashion and need to be part of it. The $2 \mathrm{~d}$ cause, college students realise that almost all of records circulating at the Internet is in English, and that they start to recognize positive phrases which can be beneficial in gaining knowledge of English abilities. The 0.33 purpose, the Internet additionally gives hands-on language exercise revel in through offering college students with purposeful communicative studies so as to be capable of encourage them to apply English in regular lifestyles. The following will provide an explanation for the motives for the significance of the Internet for coaching English: 1. Learning to apply a laptop through itself may be motivating to analyze English. Based at the revel in of Muehleisen (1997) that there are nonetheless many college students who aren't but capable of use computer systems, however while they're taught how vital it's miles to apprehend computer systems, on common college students can be involved and need to grasp them.2. The Internet locations English as an global language. Students can recognize that almost all of records circulating at the Internet is in English. They additionally determined that they may use English as a medium to learn how to talk with different humans round the sector, and now no longer simplest in English-talking nations. Of path college students need to speak with local speakers, however a number of the college students choose to talk with humans from different nations.3. The Internet is an interactive medium. Although college students are withinside the experimental degree in surfing the Internet, with out understanding it they were wondering and seeking to use sure phrases in English. In addition, nearly all web sites offer email addresses, so college students can ask questions or ship comments.4. Facilities for the use of the Internet are exceedingly smooth to obtain. In a few evolved nations, Internet centers are to be had in pclaboratories. However, the equal situations have now no longer completely existed in growing international locations, which includes Indonesia. However, with present day technological trends, nearly each faculty already has a laptop laboratory, however isn't always but linked to the Internet. Whereas the power is without difficulty implemented with the aid of using connecting a pc through smartphone or wi-fi community. Required Components 1. Integration the maximum essential aspect withinside the English language training application need to be incorporated, now no longer a further software. Teachers have to be without delay worried with the software, as an instance giving homework and interactions 2. Computer Skills Students do now no longer 
constantly have understanding in the use of computer systems. But the maximum crucial issue is to educate easy steps a way to use computer systems and the Internet.3. Active Teacher Teachers have to actively encourage college students to apply the Internet. If necessary, the instructor ought to make handouts or commands the use of computer systems and the Internet, specially a way to use an internet browser or ship email. Techniques for Teaching Writing with the Help of the Internet Three fundamental factors in language coaching, specifically writing, specifically web sites that scholars will use to discover the statistics they want. want, electronic mail on the way to be used to ship and acquire facts from everywhere, and net publishing that is used to submit the scholar's paintings. It must be remembered that the usage of computer systems in language coaching isn't always meant as an opportunity to language coaching, however simplest as a device to train language. The use of computer systems will increase language coaching itself, particularly if it's miles mixed with the usage of the Internet. With the Internet, college students now no longer most effective get new "toys", however also can get extra real and exciting facts. But the maximum essential factor is how instructors can actively discover the capability of college students and make use of facts era to acquire the coaching dreams which have been set in an modern and thrilling manner.

In the practice of using technology in the classroom, the teacher is the main character in the teaching and learning process have unique role in integrating English lessons with technology. According to Budiman et al., (2018), the practice of teachers in the use of technology has close relationship with how teachers perceive technology teachers have a different view good for the benefits of integrating technology in learning. However, even though the teachers have views positive towards the use of technology in the classroom and realize the benefits of technology, but in fact still many teachers are reluctant to use technology in they classroom learning. Teachers take advantage of technology for various reasons, such as teacher's interest in using technology, today's demands, nee benefit from technology and also because of the teacher feel confident when integrating English lessons with technology.

\section{Methodology}

The research methodology adopts a scope review study, which is a literature review process between new theories and ideas. The purpose of the scope review study is to find all material relatedto the topic without any limitations (Arksey \& O'Malley, 2005). The scoping study method refers to the identification of some relevant literature that is independent of the research design. Based on this approach, this study analyzes and reviews the literature relating to multimedia technology in teaching English. For the first step, the researcher explained the 
notion of technological integration, then proceeded to trace evidence from previous research on the benefits of multimedia technology in teaching English. In the final section also explained the multimedia technology-based teaching framework that contains activities that can be applied in Language teaching.

This research that examines or review critically expertise, thoughts, or findings contained withinside the frame of literature academically-orientated literature, in addition to formulating his theoretical and methodological contributions to particular topics, cooper (2010). The nature of this studies is descriptive analysis, specifically: normal decomposition of the statistics that has been obtained, then given information and clarification in order that it could be understood nicely via way of means of the reader.

\section{Discussion}

\section{a. Definition and Development of Technology}

Technology is the entire means to provide goods needed for the survival and comfort of human life. Technology can be interpreted as a means used to facilitate human life and has an important role in supporting human life. According to the Big Indonesian Dictionary (KBBI), the word technology means the scientific method to achieve practical goals, applied science or the overall means to provide goods needed for the survival and comfort of human life.

Technology was initially only applied to tangible objects that had a physical presence, such as telephones, televisions, cables, and so on. But along with its development, technology has now turned invisible, but still plays an important role in human life. With technology, we can connect with anyone anywhere in real time, as if distance is now not a barrier. It is also with technological advances, we can survive during a pandemic like now, where physical meetings are not possible, with technology, meetings turn virtual, without reducing the value in them at all.

\section{b. Use of Technology in Teaching English}

In the digital world, where everything is under control Internet, it's hard to ignore existence and contribution of technology towards teaching English. Learning English is a process second language teaching that is not easy: various contributing factors and combined together for achieve success in this endeavor. To produce good results, To produce proper results, instructors need to dedicate loads effort and time to decide maximum coaching technique satisfactory, appropriate, and powerful. As using English has elevated in reputation so has the want for certified instructors to teach college students withinside the language. It is genuine that there are instructors who use 'slicing edge' era, however the majority of instructors 
nonetheless educate withinside the conventional manner. None of those conventional manners are horrific or unfavourable the college students. In truth, until date they're proving to be beneficial additionally. However, there are numerous greater possibilities for college kids to benefit self-belief exercise and make bigger themselves, specifically for ESL college students who study the language for extra than simply a laugh. For them to maintain tempo with ELT and advantage extra self assurance they need to stride into thearena of multimedia era.

\section{c. The Growth of ELT Through Technology}

21 st century is the age of globalization and is essential to comprehend on diverse overseas languages and English language comes first. English Language Teaching has been with us for decades and its importance keeps to grow, fuelled, partly through the Internet. Graddol's examine (2000) indicates that withinside the yr 2000 there have been approximately a billion English novices- however a decade later the numbers doubled. The forecast factors to a surge in English getting to know, which has peaked in 2010. The identical take a look at shows that over $80 \%$ of statistics saved at the net is in English. For the primary time there are extra Non-Native than Native customers of the language and variety of context in phrases of inexperienced persons, age, nationality, getting to know history etcetera has emerge as a defining function of ELT today. With the speedy improvement of technology and era, the rising and growing of multimedia generation and its software to coaching, offering audio, visible, animation results comes into complete play in English elegance coaching and units a good platform for reform and exploration on English coaching version withinside the new technology. It's proved that multimedia generation performs a high quality position in selling sports and tasks of scholar and coaching impact in English elegance. Technological improvements have long gone hand -inhand with the boom of English and are converting the manner wherein we talk. It is truthful to claim that the increase of the net has facilitated the boom of the English language and that this has came about at a time while computer systems are now no longer the distinctive domain names of the devoted few, however as an alternative to be had to many. With this there was a completely extensive proliferation of literature concerning using era in coaching English language. Mostly those writings unequivocally take delivery of era because the maximum important element in coaching. In a sense, a bent to emphasise on inevitable position of era in pedagogy to the quantity of obliterating human a part of trainer through era element has been very dominant. And as a end result if we forget or forget about technological trends they may maintain and possibly we can in no way be capable of capture up, regardless of our field or branch. For this cause it's far crucial for language instructors to be privy to the modern-day and fine system and to have a complete information 
of what's to be had in any given situation. Teachers can use Multimedia Technology to present greater colorful, stimulating lectures (new Horizons). There are many strategies relevant in diverse levels to language studying situation. Some are beneficial for checking out and distance schooling, and a few for coaching enterprise English, spoken English, reading, listening or interpreting. The coaching precept must be to realize new technology withinside the regions and features in which they offer some thing decisively new beneficial and by no means allow machines takeover the position of the instructor or restrict capabilities wherein greater conventional approaches are superior. There are diverse motives why all language inexperienced persons and instructors have to understand how to utilize the brand new era. Here we additionally want to emphasise that the brand new technology expand and disseminate so speedy that we can not keep away from their appeal and have an impact on in any form.

\section{d. Benefits of Using Technology in the Classroom}

It is critical to well known that scholars are already fascinated and engaged in the use of era, this creates many superb possibilities for colleges and instructors to advantage from integrating a few types of era withinside the school room and to make coaching and getting to know extra powerful. Here are a number of the primary advantages of the use of generation withinside the study room. Improves engagement When generation is incorporated into classes, college students are predicted to be greater inquisitive about the topics they're studying. Technology offers exceptional possibilities to make studying extra a laugh and fun in phrases of coaching identical matters in new methods. For instance, turning in coaching thru gamification, taking college students on digital discipline journeys and the use of different online getting to know sources. What is extra, era can inspire a extra lively participation withinside the getting to know manner which may be difficult to reap via a conventional lecture environment.

1. Improves expertise retention

Students who're engaged and inquisitive about matters they're studying, are anticipated to have a higher know-how retention. Technology can assist to inspire lively participation withinside the lecture room which is also a completely crucial element for elevated know-how retention. Different sorts of era may be used to test with and determine what works quality for college kids in phrases of keeping their information.

2. Improves knowledge retention

No one learns withinside the identical manner due to one-of-a-kind studying patterns and distinctive abilities. Technology presents exquisite possibilities for making studying extra powerful for all people with special wishes. For example, college students can study at their 
personal speed, assessment hard ideas or pass in advance in the event that they want to. What is extra, era can offer extra possibilities for suffering or disabled college students. Access to the Internet offers college students get entry to to a vast variety of sources to behavior studies in exclusive methods, which in flip can boom the engagement.

3. Encourages character gaining knowledge of

No one learns withinside the identical manner due to one-of-a-kind studying patterns and distinctive abilities. Technology presents exquisite possibilities for making studying extra powerful for all people with special wishes. For example, college students can study at their personal speed, assessment hard ideas or pass in advance in the event that they want to. What is extra, era can offer extra possibilities for suffering or disabled college students. Access to the Internet offers college students get entry to to a vast variety of sources to behavior studies in exclusive methods, which in flip can boom the engagement.

4. Students can learn useful lifestyle ability through technology

By the use of era withinside the school room, each instructors and college students can expand abilties important for the twenty first century. Students can advantage the talents they may want to achieve success withinside the future. Modern studying is ready participating with others, fixing complicated troubles, vital wondering, growing one of a kind sorts of verbal exchange and management abilities, and enhancing motivation and productivity. What is extra, generation can assist expand many sensible competencies, inclusive of growing presentations, studying to distinguish dependable from unreliable reassets at the Internet, preserving right on line etiquette, and writing emails. These are very essential capabilities that may be advanced withinside the lecture room.

\section{Conclusion}

In this paper, the researcher reviews several important issues related to the use of technology in language teaching learning. Technology is used to enhance modern style; it satisfies both visual and auditory senses of students. Multimedia technology-based English teaching is to increase students' motivation and interest in learning, which can be a practical way to involve them in language learning. The rapid development and advancement of information technology has offered a better pattern for exploring new teaching models. As a result, technology plays a very important role in teaching English In facing the era of global competition, students need to get adequate supplies. Although there are most of the teachers who still teach in the traditional way. None of these traditional manners is bad or damaging to students. Currently mastery of technology is a necessity for every human being so as not to be 
consumed by time. Likewise in the world of education, learning innovations, especially learning English can be done by utilizing the internet network in producing Technology-based learning tools.

However, there are greater possibilities for college kids to advantage the self assurance to exercise and broaden themselves, in particular for ESL college students who analyze languages for extra than simply a laugh. For them to observe ELT and benefit extra self belief, they ought to step into the arena of multimedia era. Through technology-based English learning innovations, it can provide the widest opportunities for students to hone and stimulate learning competence on an international scale. Mental attitude and independence in accessing all information learning that is needed independently exert influence in inculcating student personality values so that it doesn't always change his life with other people. Using technology to create context for teaching English has unique advantages. Teachers can engage students to become skilled in English by using innovative ELT techniques such as English songs, films, clippings, plays, advertisements, sports commentary and more. This paper emphasizes the need to make learning English easy and fun through the use of innovative technology.

\section{REFRENCES}

Arifah, A. 2014. Study on the Use of Technology in ELT Classroom:Teachers' Perspective. M.A. Thesis, Department of English and Humanities, BRAC University, Dhaka, Bangladesh.

Baytak, A., Tarman, B., \& Ayas, C. 2011. Experiencing Technology Integration in Education: Children's Perceptions. International Electronic Journal of Elementary Education, 3(2), 139-151.

https://www.iejee.com/index.php/IEJEE/article/view/233. Date accessed: June 17th, 2018.

Bialystok, E. and K. Hakuta 1999. Confounded Age: Linguistic and Cognitive Factors in Age Differences for Second Language Acquisition: Second Language Acquisition and the Critical Period Hypothesis. in D. Birdsong. (ed). New Jersey, Lawrence Erlbaum Associates.

Brumfit C, Mooh J, et al., Eds. 1984. Teaching English to Children: From Practice to Principle.England, Longman Group, Ltd. Graddol: Graddol, D. (1997). The Future of English. London: The BritishCouncil.

Arksey, H., O’Malley, L., 2005. Scoping studies: towards a methodological framework. International Journal of Social Research Methodology.

Zhanghongling ( The development tendency of the modern foreign language teaching and the computer assisted instruction. Computer-Assisted Foreign Language Education 3. 
Brown, H.D. (2001). Teaching by principles: An interactive approach to language pedagogy. Beijing: Foreign Language Teaching and Research Press.

Holec,H.(1981). Autonomy and Foreign language learning. Oxford: Pergamon.

www.ccsenet.org/journal.html, vol.1, No 4, November 2008.

Farooq, M. U., \& Soomro, A. F. (2018). Teachers and Technology: Trends in English Language Teaching in Saudi Arabia. International Journal of English Linguistics, 8(5), 10-19. https://doi.org/10.5539/ijel.v8n5p10

Fauzan, U., \& Pimada, L. H. (2018). ICT-Based Teaching of English at Madrasah Aliyah in Kalimantan. TARBIYA: Journal of Education in Muslim Society, 5(2), 193-211. https://doi.org/10.15408/tjems.v5i2.10414

Floris, F. D. (2014). Using information and communication technology (ICT) to enhance language teaching \& learning: An interview with DR. A. Gumawang Jati. TEFLIN Journal, 25(2), 139-146.

Fu, J. S. (2013). ICT in Education: A Critical literature review and its implications. International Journal of Education and Development Using Information and Communication Technology, 9(1), 112-125.

B.E. Conway, Electrochemical Capacitors: Scientific Fundamentals and Technological Applications, Kluwer AcademicrPlenum, 1999.

L.D. Raistrick, R.J. Sherman, Electrical Response of Electrochemical Capacitors based on High Surface Area Ruthenium Oxide Electrodes, Los Alamos National Laboratory, Report No. LA-UR-87-2340, 1987. 